\title{
In vivo degradation of poly L-lactic D-lactic acid and tri-methylene carbonate sheets in orbital reconstruction
}

\author{
Kun Hwang', Hyung Mook Kim² \\ ${ }^{1}$ Department of Plastic Surgery, Inha University School of Medicine, Incheon 22332, South Korea. \\ ${ }^{2}$ Department of Plastic Surgery, Inha University Hospital, Incheon 22332, South Korea.
}

Correspondence to: Dr. Kun Hwang, Department of Plastic Surgery, Inha University School of Medicine, 27 Inhang-ro, Jung-gu, Incheon 22332, South Korea. E-mail: jokerhg@inha.ac.kr

How to cite this article: Hwang K, Kim HM. In vivo degradation of poly L-lactic D-lactic acid and tri-methylene carbonate sheets in orbital reconstruction. Plast Aesthet Res 2017;4:9-12.

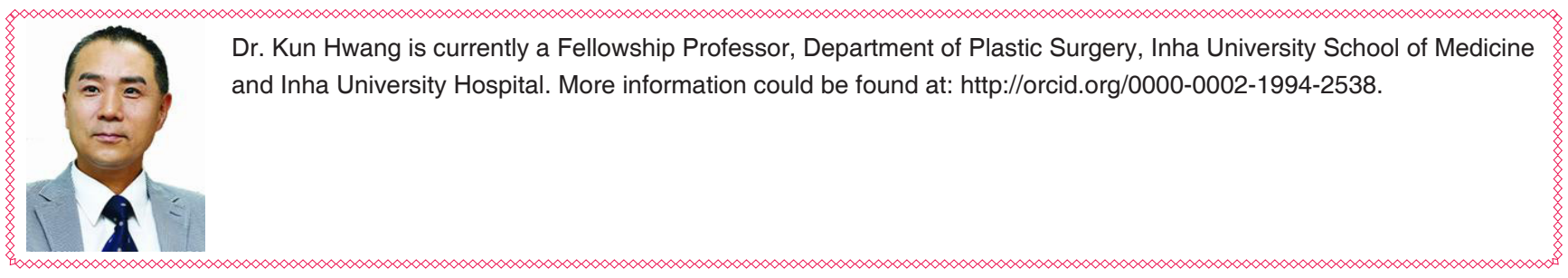

\section{Article history:}

Received: 19-09-2016

Accepted: 16-01-2017

Published: 19-01-2017

\section{Key words:}

Poly(lacticide-co-trimethylene

carbonate),

spectroscopy,

fourier transform infrared,

chromatography,

gel,

orbit,

orbital fractures

\section{ABSTRACT}

This study was conducted to evaluate changes in the composition of a poly-L-lactic D-lactic acid and trimethylene carbonate (PLDLA-TMC) sheet after insertion into the human body. A 35-year-old woman had an orbital fracture that was reconstructed using a PLDLA-TMC sheet. During iliac bone grafting for enophthalmos 190 days after the insertion, the sheet was removed and analyzed using gel permeation chromatography and Fourier transform infrared spectroscopy. The weight average molecular weight decreased (from 151,000 Da to $10,000 \mathrm{Da}$ ), as did the number average molecular weight (from $15,600 \mathrm{Da}$ to $255 \mathrm{Da}$ ). An amide functional group peaks at $1,655.43 \mathrm{~cm}^{-1}\left(1,670-1,640 \mathrm{~cm}^{-1}\right)$ and its stretch band at $1,541.26 \mathrm{~cm}^{-1}\left(1,640-1,550 \mathrm{~cm}^{-1}\right)$ newly appeared due to serum or tissue fluid incorporation. PLDLA-TMC is expected to exhibit favorable degradation properties. 


\section{INTRODUCTION}

Absorbable sheets are used to treat orbital fractures. CPS sheets [poly L-lactic D-lactic acid and trimethylene carbonate (PLDLA-TMC)] absorbable sheets (Inion Co., Tampere, Finland) are commonly used to treat trauma and in reconstructive procedures of the orbital cavity. In vivo degradation of several absorbable materials has been documented. ${ }^{[1-4]}$ However, the compositional changes (appearance of radicals, etc.) of PLDLA-TMC after insertion into the human body have not yet been described.

The aim of this paper was to assess compositional changes in a PLDLA-TMC sheet, synthesized by a ringopening polymerization process, 190 days after insertion into a human body.

\section{CASE REPORT}

\section{Patient history and sample}

A 35-year-old female patient had a pan-facial fracture due to a car accident. Upon examination, she did not show diplopia or hypoesthesia. A computed tomography scan showed a blow-out fracture of the right medial wall and floor with herniation of soft tissues [Figure 1].

Through a subciliary incision, the orbital floor and medial wall were exposed and the herniated soft tissues were

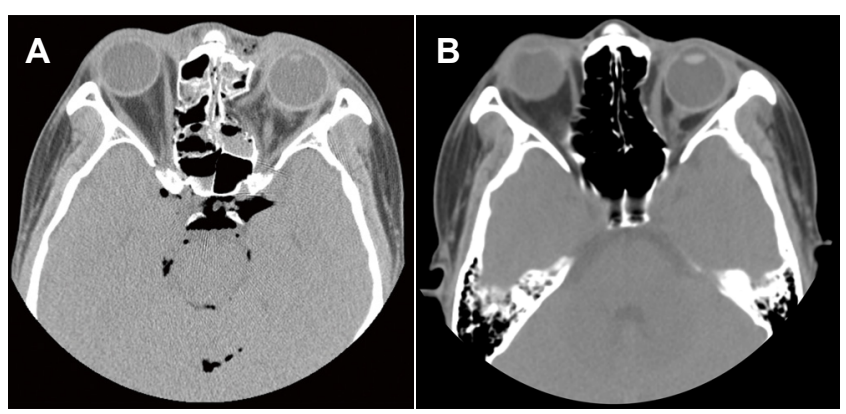

Figure 1: Axial computed tomography scans. (A) Fracture of the medial orbital wall and herniation of the soft tissue; (B) 190 days after CPS sheet insertion before secondary orbital floor reconstruction

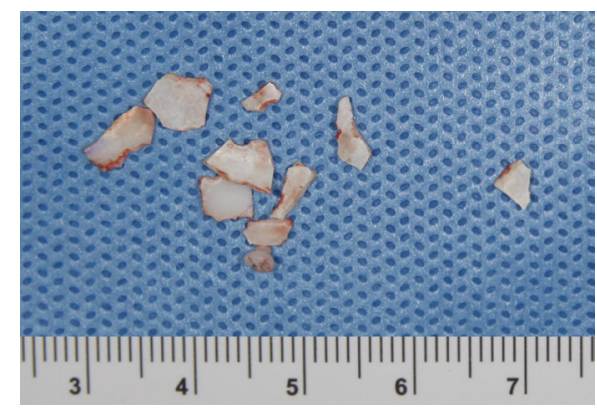

Figure 2: The removed fragile part of the sheet that had been inserted 190 days previously reduced. The floor and medial wall were reconstructed with a trimmed $(45 \mathrm{~mm} \times 33 \mathrm{~mm} \times 1.5 \mathrm{~mm})$ CPS sheet made of PLDLA-TMC (Inion Co., Tampere, Finland) [Figure 2].

Exophthalmometry on postoperative day (POD) 9 revealed a 3-mm difference (right eye, $19 \mathrm{~mm}$; left eye, $16 \mathrm{~mm}$ ). The differences in exophthalmometry on POD 98 and POD 154 were $7 \mathrm{~mm}$ (right eye, $18 \mathrm{~mm}$; left eye, $11 \mathrm{~mm}$ ) and $8 \mathrm{~mm}$ (right eye, $19 \mathrm{~mm}$; left eye, $11 \mathrm{~mm}$ ), respectively. On POD 189 (1 day before the secondary operation), the difference was $5 \mathrm{~mm}$ (right eye, $18 \mathrm{~mm}$; left eye, $13 \mathrm{~mm}$ ).

Secondary reconstruction of the orbital floor was performed with an iliac bone graft 190 days after insertion. During the secondary operation, the fragile part of the CPS sheet that had been previously inserted was removed.

Analysis of molecular weight and components of the PLDLA-TMC sheet

The sample was analyzed using gel permeation chromatography (GPC) (Waters GPC system; Waters Co., Milford, MA, USA) to characterize changes in its molecular weight.

Fourier transform infrared spectroscopy (FT-IR) (JASCO FT-IR 4100; JASCO Co., Tokyo, Japan) was used to evaluate compositional changes that occurred due to being in the body.

The principles outlined in the Declaration of Helsinki were followed in this study.

\section{Gel permeation chromatography}

In the specimen from the operation, the weight average molecular weight $(\mathrm{Mw})$ decreased from 151,000 Da to $10,000 \mathrm{Da}$, and the number average molecular weight $(\mathrm{Mn})$ decreased from 15,600 Da to $255 \mathrm{Da}$. The polydispersity index $(\mathrm{Mn} / \mathrm{Mn})$ thus increased from 9.96 to 40.22 [Figure 3].

\section{Fourier transform infrared spectroscopy}

In the post-insertion spectrum, $1,655.43 \mathrm{~cm}^{-1}$ and $1,541.26 \mathrm{~cm}^{-1}$ peaks appeared, which are thought to be an amide peak $\left(1,670-1,640 \mathrm{~cm}^{-1}\right)$ and its stretch bend $\left(1,640-1,550 \mathrm{~cm}^{-1}\right)$, respectively [Figure 4].

\section{DISCUSSION}

Matsumura prepared poly(lactide-co-trimethylene carbonate) through the lipase-catalyzed ring-opening copolymerization of lactide and trimethylene carbonate, increasing the carbonate content from 0 to $100 \%{ }^{[5]}$ 

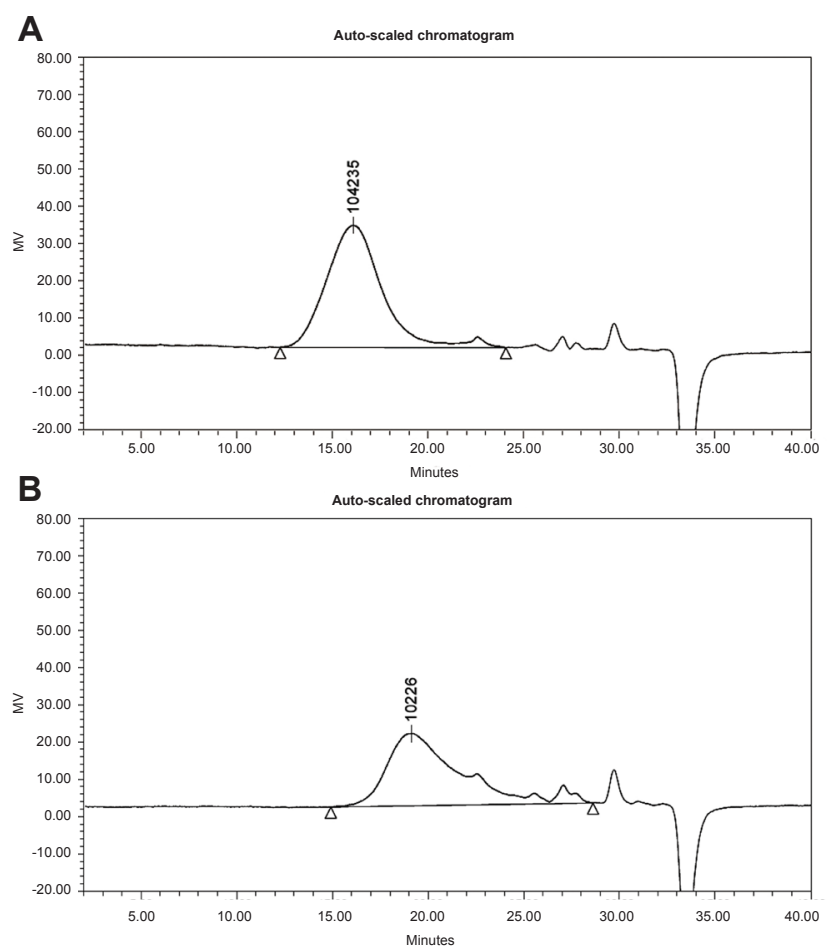

Figure 3: Gel permeation chromatograms. (A) Pre-insertion; (B) 190 days post-insertion

Yang et al. ${ }^{[6]}$ reported that hemolysis tests showed that all homopolymers and copolymers presented very low hemolytic ratios, indicating good hemolytic properties. Adhesion and activation of platelets were observed on the surface of polylactic acid, polycaprolactone (PCL), poly L-lactic acid (PLLA) and trimethylene carbonate (TMC) (PLLA-TMC), and poly-DL-lactide (PDLLA)TMC films, while fewer platelets and less activation were found on poly(TMC). The most interesting results were obtained with PCL-TMC, which exhibited the lowest degree of activation, with few adhered platelets, in agreement with its outstanding anticoagulant properties. ${ }^{[6]}$

Guo et al., ${ }^{[7]}$ in an experiment using 144 Wistar rats, stated that the molecular weight of PLLA decreased rapidly, from 72,000 to $68,000 \mathrm{kDa}$ in the first 2 days and to $32,000 \mathrm{kDa} 15$ days later. Similar molecular weight decreases were obtained for PLLA-TMC and PDLLATMC copolymers, although PLLA-TMC appeared more resistant to hydrolytic degradation. Beyond 60 days, the molecular weight of PDLLA-TMC decreased below $10,000 \mathrm{kDa}$, in agreement with the rapid mass loss observed in this period. ${ }^{[7]}$ In our study, the weight average molecular weight (Mw) decreased from 151,000 to $10,000 \mathrm{Da}$.

Pêgo et al., ${ }^{[8]}$ in an in vitro study, reported that elastomeric (co)polymers of TMC and D,L-lactide

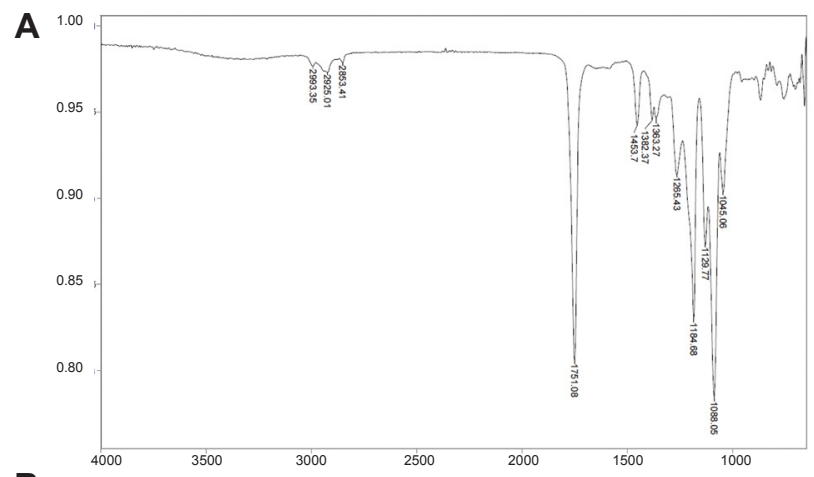

B

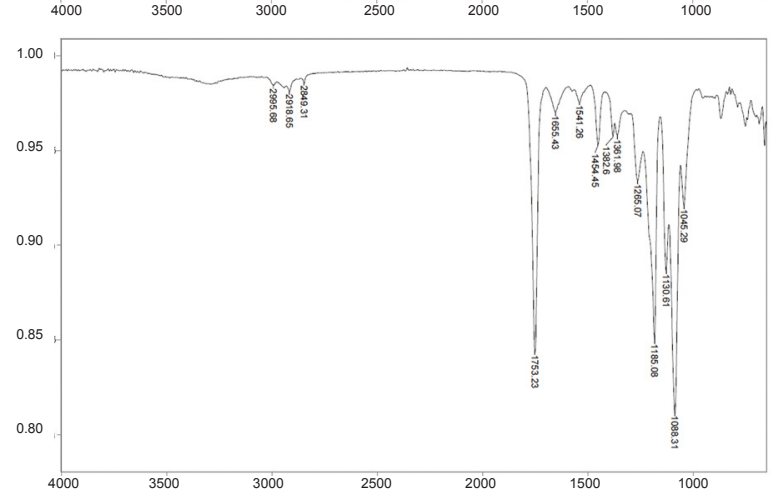

Figure 4: Fourier transform infrared spectrums. (A) Pre-insertion: (B) 190 days post-insertion

(DLLA) scaffolds were dimensionally stable during incubation in phosphate-buffered saline at $37^{\circ} \mathrm{C}$. The number average molecular weight $(\mathrm{Mn})$ of the polymer decreased gradually from $2.0 \times 10^{5} \mathrm{Da}$ to $0.3 \times 10^{5} \mathrm{Da}$ over a period of 4 months. Pego et al. ${ }^{[8]}$ added that the poly $(T M C)$ specimens were extensively degraded after 3 weeks and, as confirmed by histology, totally resorbed in less than 1 year. He concluded that in vivo, poly $(T M C)$ is degraded via surface erosion involving cellular-mediated processes. The degradation of the copolymers was slower than that of poly(TMC), taking place via autocatalyzed bulk hydrolysis, preferentially of ester bonds. The TMC-DLLA copolymer was degraded 20 times faster than the TMC-caprolactone copolymer. Significant mass loss was only observed for the TMC-DLLA copolymer, which underwent $96 \%$ mass loss in 1 year. ${ }^{[0]}$

In our study, GPC was used to find that the $\mathrm{Mw}$ of PLDLA-TMC decreased from 151,000 Da to 10,000 Da 190 days after insertion. This suggests that that PLDLATMC has favorable degradation properties.

Originally, PDLLA-TMC did not have an amide peak $\left(1,670-1,640 \mathrm{~cm}^{-1}\right)$ or its stretch bend $\left(1,640-1,550 \mathrm{~cm}^{-1}\right)$. In our study, FT-IR of the post-insertion spectrum showed new $1,655.43 \mathrm{~cm}^{-1}$ and $1,541.26 \mathrm{~cm}^{-1}$ peaks, which are thought to be an amide peak $\left(1,670-1,640 \mathrm{~cm}^{-1}\right)$ and its stretch bend $\left(1,640-1,550 \mathrm{~cm}^{-1}\right)$, respectively. 
Chapanian and Amsden ${ }^{[10]}$ investigated the potential of osmotic pressure-driven release of proteins from poly(TMC-co-DLLA) elastomers with varying amounts of DLLA, using bovine serum albumin (BSA) as a model protein. The BSA was co-lyophilized with either trehalose or trehalose combined with sodium chloride as osmotigens to produce particles with sufficient osmotic activity.

The reduced molecular weights in the post-insertion specimen suggest that PLDLA-TMC has favorable degradation properties. The newly appeared bands are thought to be an amide peak $\left(1,670-1,640 \mathrm{~cm}^{-1}\right)$ and its stretch bend $\left(1,640-1,550 \mathrm{~cm}^{-1}\right)$, resulting from serum or tissue fluid incorporation.

\section{Financial support and sponsorship}

This study was supported by Inha University (INHAResearch Grant).

\section{Conflicts of interest}

There are no conflicts of interest.

\section{Patient consent \\ Obtained.}

\section{Ethical approval}

All procedures performed in studies involving human participants were in accordance with the ethical standards of the institutional and/or national research committee and with the 1964 Helsinki Declaration and its later amendments or comparable ethical standards.

\section{REFERENCES}

1. van der Elst M, Dijkema AR, Klein CP, Patka P, Haarman HJ. Tissue reaction on PLLA versus stainless steel interlocking nails for fracture fixation: an animal study. Biomaterials 1995;16:103-6.

2. Pistner H, Bendix DR, Mühling J, Reuther JF. Poly(L-lactide): a longterm degradation study in vivo. Part III. Analytical characterization. Biomaterials 1993;14:291-8.

3. Imola MJ, Hamlar DD, Shao W, Chowdhury K, Tatum S. Resorbable plate fixation in pediatric craniofacial surgery: long-term outcome. Arch Facial Plast Surg 2001;3:79-90.

4. Landes CA, Ballon A, Roth C. Maxillary and mandibular osteosyntheses with PLGA and P(L/DL)LA implants: a 5-year inpatient biocompatibility and degradation experience. Plast Reconstr Surg 2006;117:2347-60.

5. Matsumura S, Tsukada K, Toshima K. Novel lipase-catalyzed ringopening copolymerization of lactide and trimethylene carbonate forming poly(ester carbonate)s. Int J Biol Macromol 1999;25:161-7.

6. Yang J, Liu F, Tu S, Chen Y, Luo X. Lu Z, Wei J, Li S. Haemo- and cytocompatibility of bioresorbable homo- and copolymers prepared from 1,3-trimethylene carbonate, lactides, and epsilon-caprolactone. J Biomed Mater Res A 2010;94:396-407.

7. Guo Q, Lu Z, Zhang Y, Li S, Yang J. In vivo study on the histocompatibility and degradation behavior of biodegradable poly(trimethylene carbonate-co-D,L-lactide). Acta Biochim Biophys Sin (Shanghai) 2011;43:433-40.

8. Pêgo AP, Siebum B, Van Luyn MJ, Gallego y Van Seijen XJ, Poot AA, Grijpma DW, Feijen J. Preparation of degradable porous structures based on 1,3-trimethylene carbonate and D,L-lactide (co) polymers for heart tissue engineering. Tissue Eng 2003;9:981-94.

9. Pêgo AP, Van Luyn MJ, Brouwer LA, van Wachem PB, Poot AA, Grijpma DW, Feijen J. In vivo behavior of poly(1,3-trimethylene carbonate) and copolymers of 1,3-trimethylene carbonate with D,Llactide or epsilon-caprolactone: degradation and tissue response. $J$ Biomed Mater Res A 2003;67:1044-54.

10. Chapanian R, Amsden BG. Osmotically driven protein release from photo-cross-linked elastomers of poly(trimethylene carbonate) and poly(trimethylene carbonate-co-d,1-lactide). Eur J Pharm Biopharm 2010;74:172-83. 